(C) 2021, The Authors. Published by Elsevier Inc. and Fass Inc. on behalf of the American Dairy Science Association ${ }^{\circledR}$. This is an open access article under the CC BY-NC-ND license (http://creativecommons.org/licenses/by-nc-nd/4.0/).

\title{
Pain in the weeks following surgical and rubber ring castration in dairy calves
}

\author{
Emeline Nogues, 일 Marina A. G. von Keyserlingk, (1) and Daniel M. Weary* () \\ Animal Welfare Program, Faculty of Land and Food Systems, University of British Columbia, 2357 Main Mall, Vancouver, BC Canada V6T 1Z4
}

\begin{abstract}
Many male dairy calves are castrated when reared for beef production, but for dairy breeds the assessment of the longer-lasting pain associated with this procedure has received little scientific attention. In this study we assessed 2 methods: surgical ( $\mathrm{n}=10$ calves) and rubber ring $(\mathrm{n}=11)$. All calves were castrated at $28 \mathrm{~d}$ of age using multimodal pain control. During the 8 wk that followed, we recorded wound healing, local inflammation, body weight, milk and calf starter intake, lying time, and wound-directed behavior. Surgical wounds were fully healed on average 4 wk after the procedure, but only 1 calf in the rubber ring treatment fully healed within the 8 -wk study. Inflammation was greater after rubber ring castration; skin temperature in the area around the lesion was $1.7 \pm 0.35^{\circ} \mathrm{C}$ (mean \pm standard deviation) higher than for the surgical treatment. Compared with surgically castrated calves, those castrated by rubber ring gained less weight over the study period (on average $11.9 \pm 5.1 \mathrm{~kg}$ less), a difference due in part to lower intake of calf starter (on average $1.8 \pm 0.6 \mathrm{~kg}$ less). Calves in the rubber ring treatment spent less time lying down (on average $4.2 \pm 1.2 \%$ fewer scans per day) and licked their lesions more frequently (on average $16.0 \pm 3.3$ more licks per day). We conclude that the rubber ring calves experienced more pain in the weeks following the procedure and thus recommend that surgical castration be favored for preweaning dairy calves.
\end{abstract}

Key words: animal welfare, pain behavior, scrotal lesion, calf growth

\section{INTRODUCTION}

Most dairy farms do not retain male calves; instead these calves are typically sold within the first weeks of life (Renaud et al., 2017). Male dairy calves form an important part of the beef industry worldwide; that role is likely to become more prevalent with increased use of sexed semen for genetically superior cows and

Received January 4, 2021

Accepted August 5, 2021.

*Corresponding author: danweary@mail.ubc.ca beef semen for the remainder of the herd. Data specific to dairy breeds is lacking, but cattle inventory data from the United States and Canada indicates that $88 \%$ of males over $500 \mathrm{lb}$. have been castrated (USDANASS, 2021). Although this procedure has perhaps not yet been considered a dairy issue, we suggest that the dairy industry has a role in understanding the pain associated with castration and in ensuring its mitigation.

Common methods of castration are surgical (which involves an incision of the scrotum and complete removal of the testes) and nonsurgical (typically using either a rubber ring or band for constriction). The application of the rubber ring or band interrupts blood flow to the scrotum and testes, causing atrophy and necrosis of the tissues, which eventually slough off. The latter method is attractive to farmers, as it is cheap, effective, and easy to apply to young calves (Stafford and Mellor, 2005). This method also induces fewer obvious signs of intraoperative pain compared with the surgical method (e.g., less struggling; Petherick et al., 2015), leading some to perceive it as less painful (Spooner et al., 2012). Results of scientific studies (mostly on beef calves) indicate that both methods cause postoperative pain, as assessed by increased plasma cortisol and behavioral responses such as restlessness, abnormal postures, reduced stride length, and wound-directed behaviors (e.g., lesion licking and kicking; Robertson et al., 1994; Molony et al., 1995; Fisher et al., 2001; Meléndez et al., 2017).

Local anesthetics and nonsteroidal anti-inflammatory drugs (NSAID) mitigate pain responses in the hours after the procedure (Stafford et al., 2002). However, the wound healing process can last weeks (Fisher et al., 2001; Mintline et al., 2014), and the pain experienced over this period has received little scientific attention, perhaps because of the challenges associated with its assessment. Average daily gains are reduced by castration regardless of method (Warnock et al., 2012), and this effect is more pronounced when calves are castrated later in life (Bretschneider, 2005). Most studies on preweaning calves have used animals suckling from the dam and under extensive rearing conditions (as is common in the beef industry), so little is known about how feed intake is affected, a variable likely to influence weight gain. A few studies have assessed longer-term 
pain through behavioral observations, but differences in the sampling methods make between-method comparisons challenging. Overall, results suggest that nonsurgical methods induce pain for longer than surgical castration (Marti et al., 2017, 2018).

The aim of the current study was to compare pain responses of preweaning dairy calves in the weeks following rubber ring and surgical castration. We hypothesized that castrated calves would show signs of pain after both methods but that these signs (i.e., reduced weight gain, restlessness, and frequent wound-directed behaviors) would persist longer in calves castrated with a rubber ring because of the prolonged duration of healing and inflammation.

\section{MATERIALS AND METHODS}

The study was approved by the University of British Columbia's Animal Care Committee (no. A18-0376) and cared for according to the guidelines outlined by the Canadian Council of Animal Care (2009) at the University of British Columbia Dairy Education and Research Centre (Agassiz, BC, Canada) between February and December 2019.

\section{Animals and Housing}

Twenty-four male Holstein calves were enrolled. We selected a sample size of 12 animals per treatment based on previous literature on pain following castration; no preliminary power analysis was conducted. Calves (BW $44 \pm 5.4 \mathrm{~kg}$; herein reported as mean $\pm \mathrm{SD}$ ) were separated from their dam and fed $4 \mathrm{~L}$ of colostrum within 6 $\mathrm{h}$ of birth. Calves were kept in individual pens $(1 \times 1.5$ $\mathrm{m})$ bedded with fresh sawdust for the first $5 \mathrm{~d}$ of life. On d 3, calves were sedated (Rompun, 2\%, Bayer Inc.; $0.25 \mathrm{mg} / \mathrm{kg}$ of BW) immediately before caustic paste disbudding (Dr. Naylor's Dehorning Paste, H. W. Naylor Company Inc.), and received an NSAID (0.5 mg/ $\mathrm{kg}$ meloxicam s.c.; Metacam, $20 \mathrm{mg} / \mathrm{mL}$, Boehringer Ingelheim) upon completion of the procedure and 24 $\mathrm{h}$ later. On d 3, calves also received an intranasal respiratory vaccine (Inforce 3, Zoetis Canada Inc.). On d 5 , calves were moved to a $35-\mathrm{m}^{2}$ group pen with 10 animals per pen ( 3 groups were used; both castration methods were applied in each pen). Throughout the experiment, calves were provided $12 \mathrm{~L} / \mathrm{d}$ of whole pasteurized milk and ad libitum access to calf starter (HiPro Medicated, Hi-Pro Feeds Inc.). In the group pens both were provided from an automated feeder (CF 1000 CS Combi, DeLaval Inc.). Calves also had ad libitum access to farm hay (from a rack) and to water (in the group pens from an Insentec Roughage Intake Control water-weigh trough). Fresh sawdust was added weekly to the group pen.

\section{Castration Procedure}

Calves were pseudo-randomly assigned to either rubber ring or surgical castration, balancing across group pens, and, so that the mean birth weight in both treatments was approximately equal (rubber ring: $43 \pm 6.2$ $\mathrm{kg}$; surgical: $45 \pm 4.6 \mathrm{~kg})$. At $28( \pm 1)$ d of age, calves were moved to a separate pen and castrated; mean body weights at the time of castration were equal in both treatments (rubber ring: $68 \pm 6.0 \mathrm{~kg}$; surgical: 68 $\pm 6.0 \mathrm{~kg}$ ). All calves were sedated using a subcutaneous injection of xylazine (Rompun, 2\%, Bayer Inc.; 0.25 $\mathrm{mg} / \mathrm{kg}$ of BW). When recumbent and showing eyeball rotation, calves were administered $1.5 \mathrm{~mL}$ of a local anesthetic ( $2 \%$ lidocaine, Ayest Veterinary Labs) in each testis and $2 \mathrm{~mL}$ subcutaneously at the base of the scrotum. After $10 \mathrm{~min}$, either a rubber ring was applied on the neck of the scrotum with an elastrator or the testes were surgically removed. Surgical castration consisted of excising the distal third of the scrotum with a scalpel and pulling out the testes, ripping the spermatic cord. The excision site was left open to facilitate draining and healing. All calves received an NSAID upon completion of the procedure $(0.5 \mathrm{mg} / \mathrm{kg}$ meloxicam s.c.; Metacam, $20 \mathrm{mg} / \mathrm{mL}$, Boehringer Ingelheim). Calves were maintained in isolation until they had recovered from the sedative and were able to walk unassisted back to the group pen. The procedures began at $0930 \mathrm{~h}$, and total time out of the group pen averaged $1.7 \pm 0.6 \mathrm{~h}$.

\section{Clinical Measures}

On the day before castration, the day after, and once weekly thereafter for $8 \mathrm{wk}$, calves were brought into a scale where we performed a clinical assessment that included weighing the animal, taking a photograph of the wound to assess healing, and recording a thermal video of the scrotal area to assess inflammation. A single photograph taken with a smartphone camera from a distance of approximately $0.5 \mathrm{~m}$ from the scrotal area was used for scoring; the camera was positioned so that the wound was clearly visible and the image focused. All photographs were scored with 2 scales from Marti et al. (2017; one 5-point scale per castration method) by 2 observers familiarized with those scales; any discrepancies in score were resolved by consensus. A 1-min video recording of the scrotal area was taken using an infrared thermal imaging camera (FLIR T650sc, FLIR Systems USA); recordings were analyzed with the FlirResearchIR software 4.40 (FLIR Systems USA), again by 2 observers (intraclass correlation coefficient $=0.75 ;$ CI: $0.35-0.92)$. Distance between the wound and the camera was kept at approximately $0.5 \mathrm{~m}$, and the ambient temperature and relative humidity were 
set in the software during analysis. At 7 time points (approximately every $10 \mathrm{~s}$ while the image was in focus) an ellipse $(30 \times 30$ pixels $)$ was placed around the site of the wound, and the maximum temperature within the ellipse was recorded. These 7 measures were averaged to provide a weekly mean that was used to assess inflammation.

\section{Behavioral Measures}

Two cameras were placed $8 \mathrm{~m}$ above each group pen (WV-CW504SP, Panasonic) and were set to record continuously (GV-Remote Viewlog, Geovision Inc.). The behavior of each individual calf in the group pen was scored for $24 \mathrm{~h}$ once weekly throughout the 8-wk study. Calves were identified using their unique coat pattern. Posture (i.e., standing or lying) was scored using instantaneous scan sampling at 5-min intervals, allowing for a good estimate of standing-lying transitions (Mitlöhner et al., 2001). All occurrences of lesion licking (i.e., wound-directed behavior) were counted. Lesion licking was defined as the calf holding one rear leg up and putting his head under that leg in the vicinity of the scrotal area. Four observers, all blind to treatment, recorded activity and wound-directed behavior. All 4 observers showed excellent reliability for activity (based on a sample of 288 scans; Cohen's $\kappa=1$ ), and good reliability for lesion lickings (estimated using a sample of 8 videos of $24 \mathrm{~h}$ each; intraclass correlation coefficient $=$ 0.75; CI: 0.48-0.94). Intake of milk (measured in liters per day) and calf starter (measured on an as-fed basis in kilograms per day) were recorded automatically by the feeders, and data on the day of behavioral observation and the following day were averaged to provide a weekly estimate.

\section{Statistical Analysis}

Calf was treated as the experimental unit in all analyses. The final sample included 21 calves, 10 castrated surgically and 11 with the rubber ring (2 calves from the surgical group and 1 calf from the rubber ring groups were excluded due to signs of a prolonged respiratory infection). The following data were missing due to errors during collection: lesion lickings and time spent lying for 2 rubber ring calves (both $21 \mathrm{~d}$ after castration), scrotal temperature for 1 rubber ring calf $42 \mathrm{~d}$ after castration and for 2 rubber ring calves 56 $\mathrm{d}$ after castration, and ADG and wound healing for 1 rubber ring calf $56 \mathrm{~d}$ after castration. Data were analyzed using SAS software (version 9.4, SAS Institute Inc.). All outcome variables were screened graphically, and outliers were identified as values that exceeded 3 interquartile ranges (PROC UNIVARIATE). On this basis, 2 high values for the variable lesion licking were capped at the third-highest value +1 .

Differences in maximal scrotal temperature, ADG, milk and calf starter consumption, time spent lying, and frequency of lesion licking were analyzed using repeated measures mixed models with week (considered as continuous; 1 level), treatment (2 levels; surgical and rubber ring), and the interaction of week and treatment as fixed effects (PROC MIXED). The covariance structure was selected as either autoregressive or compound symmetry, depending on model fit (as assessed using the Akaike information criterion). First-order interaction of week by treatment was assessed and maintained in all models even when not significant, but only significant interactions are reported herein. Model assumptions were assessed by graphically examining the residuals. The variables lesion licking and calf starter consumption were normalized using square-root transformation. Results are reported with the $F$-statistic (degrees of freedom in the format $\left.F_{\text {treatment df, error df }}\right), P$-value, least squares means, and SE. The dataset and the code for analysis in SAS are available for consultation (https:/ /doi.org/10.5683/SP3/4VOZKN; Nogues et al., 2021).

\section{RESULTS}

\section{Wound Healing and Inflammation}

The wounds of surgically castrated calves fully healed during the experimental period, on average $28 \pm 6.6 \mathrm{~d}$ (mean $\pm \mathrm{SD}$ ) after castration. Over the $56 \mathrm{~d}$ of the experiment, slough-off of the necrotic tissue resulting from rubber ring castration was observed in 8 out of 11 calves, and full healing of the wound was observed in only 1 individual (Table 1 ).

We found an effect of week $\left(F_{1,142}=6.21, P=0.014\right)$ and treatment $\left(F_{1,19}=23.21, P=0.0001\right)$ on the maximum scrotal temperature recorded; inflammation reduced over time, and more inflammation was caused by

Table 1. Number of days after surgical ( $\mathrm{n}=10$ calves) or rubber ring ( $\mathrm{n}=11$ calves) castration to achieve each healing score for the first time (with scores ranging from 1 to 5 ); calves were assessed over $56 \mathrm{~d}$

\begin{tabular}{lrrrrrrr}
\hline & \multicolumn{2}{c}{ Surgical castration } & & \multicolumn{3}{c}{ Rubber ring castration } \\
\cline { 2 - 3 } \cline { 6 - 8 } Score & $\mathrm{n}^{1}$ & Mean & SD & & $\mathrm{n}^{1}$ & Mean & SD \\
\hline 1 & 6 & 1 & 0.0 & & 11 & 1 & 0.0 \\
2 & 9 & 6 & 2.7 & & 11 & 10 & 3.5 \\
3 & 9 & 12 & 4.7 & & 11 & 32 & 7.2 \\
4 & 8 & 19 & 5.0 & & 8 & 48 & 6.9 \\
5 & 10 & 28 & 6.6 & & 1 & 56 & - \\
\hline
\end{tabular}

${ }^{1} \mathrm{n}$ varied for each score, as calves were scored weekly, and calves could transition across more than one score from one week to the next. All 10 surgically castrated calves achieved a score of 5 within the experimental period, but this score was achieved by only 1 calf castrated with rubber ring. 
the rubber ring (average over the 8 wk: $37.3 \pm 0.25^{\circ} \mathrm{C}$ ) compared with the surgery $\left(35.6 \pm 0.25^{\circ} \mathrm{C}\right)$.

\section{Growth and Feed Intake}

No effect of week on ADG was observed (Figure 1; $\left.F_{1,144}=1.93, P=0.17\right)$, but an effect of the castration method was detectable $\left(F_{1,19}=6.08, P=0.023\right)$, with calves in the rubber ring treatment growing more slowly $(0.2 \pm 0.09 \mathrm{~kg} / \mathrm{d}$ less than the surgical treatment). As a result of this difference in ADG, calves in the surgical treatment gained $53.0 \pm 3.16 \mathrm{~kg}$ over the 8 -wk study period, versus $41.2 \pm 3.99 \mathrm{~kg}$ for the rubber ring treatment.

There was no effect of week $\left(F_{1,145}=0.47, P=0.49\right)$ or treatment $\left(F_{1,19}=0.98, P=0.33\right)$ on milk intake. Milk intake averaged $8.9 \pm 0.34 \mathrm{~L} / \mathrm{d}$ for calves in the surgical treatment versus $8.4 \pm 0.32 \mathrm{~L} / \mathrm{d}$ for those in the rubber ring treatment.

An effect of both week $\left(F_{1,145}=61.23, P<0.0001\right)$ and treatment $\left(F_{1.19}=10.96, P=0.0037\right)$ on calf starter intake was observed, with calves increasing their intake over time and calves in the surgical treatment eating more than those in the rubber ring treatment. Total calf starter intake over the 8-wk period averaged $3.0 \pm$ $0.51 \mathrm{~kg}$ for calves in the surgical treatment versus $1.3 \pm$ $0.33 \mathrm{~kg}$ for those in the rubber ring treatment.

\section{Behavior}

We detected an effect of both week $\left(F_{1,143}=24.25, P\right.$ $<0.0001)$ and treatment $\left(F_{1,19}=11.68, P=0.0029\right)$ on

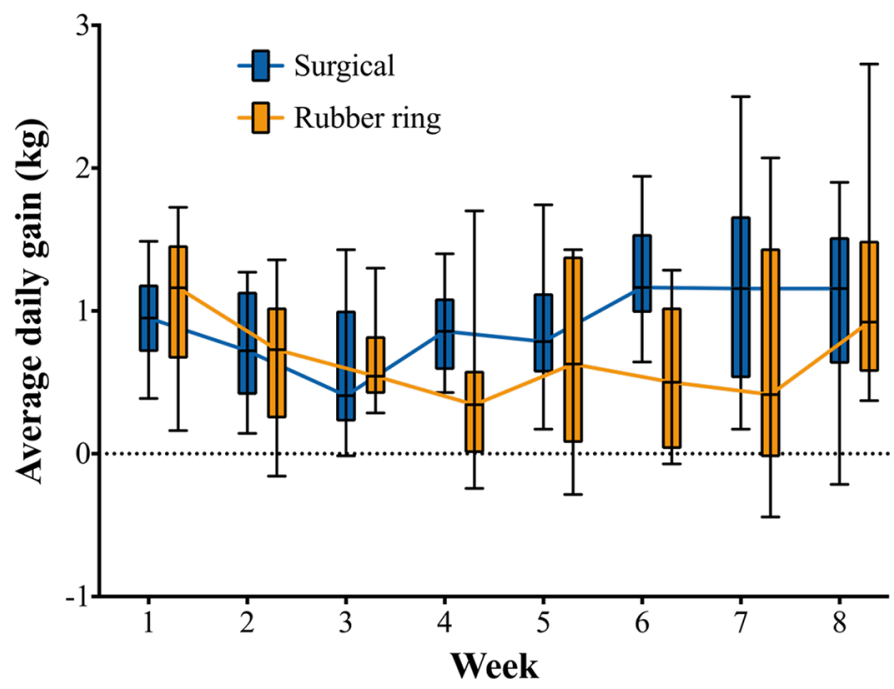

Figure 1. Average daily BW gain $(\mathrm{kg})$ of dairy calves during the 8 wk following either surgical castration $(\mathrm{n}=10)$ or rubber ring castration $(\mathrm{n}=11)$. Boxes illustrate the first and third quartiles, the central line indicates the median, and the whiskers the minimum and maximum values.
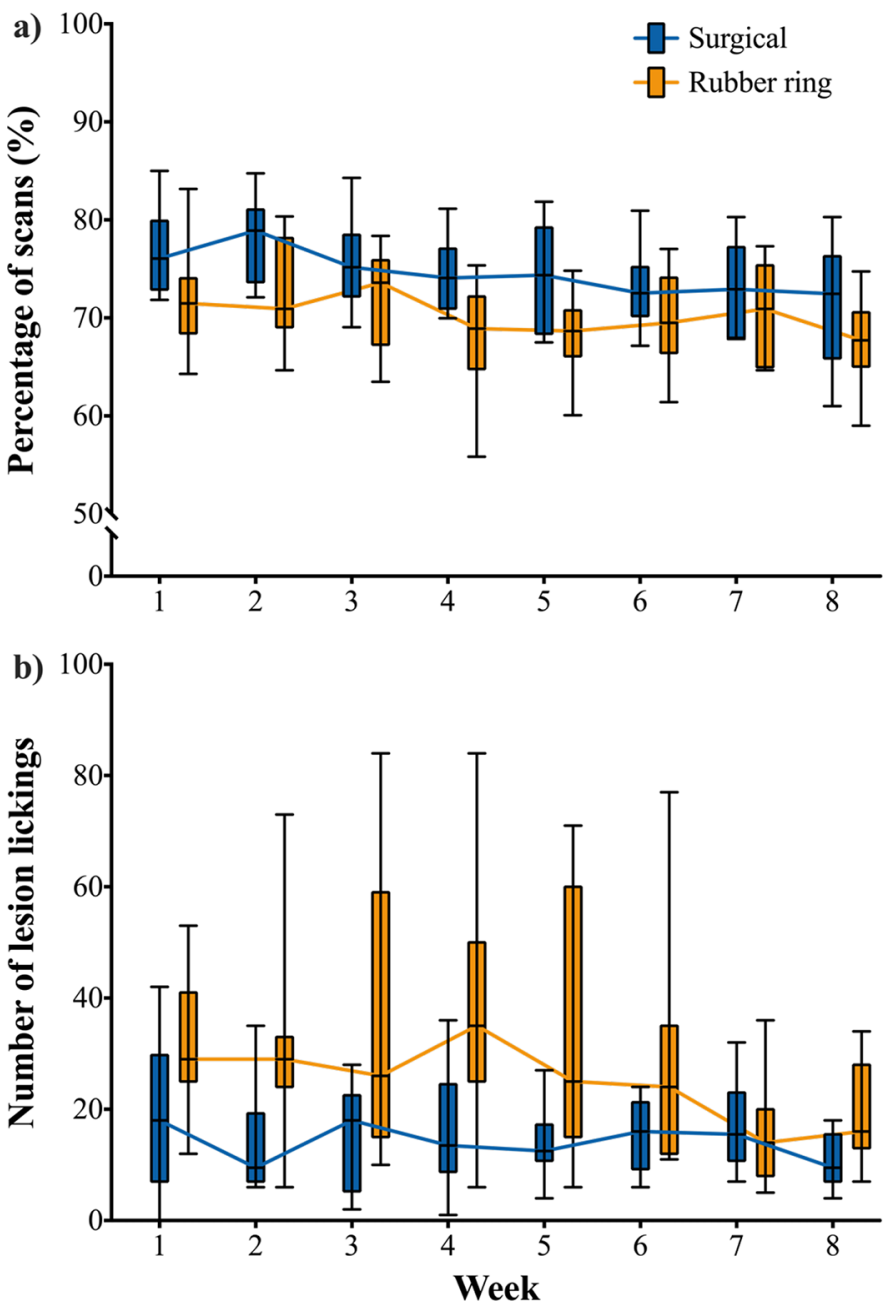

Figure 2. (a) Time spent lying down (expressed as a percentage of scans in which calves were recumbent) and (b) frequency of lesion licking. Results are shown in relation to week following surgical castration $(\mathrm{n}=10)$ or rubber ring castration $(\mathrm{n}=11)$. Boxes illustrate the first and third quartiles, the central line indicates the median, and the whiskers the minimum and maximum values.

time spent lying down (Figure 2a), with a decline over the 8-wk period; calves in the rubber ring treatment spent less time lying down $(70.3 \pm 0.85 \%$ vs. $74.5 \pm$ $0.89 \%$ of scans for surgically castrated calves, a difference corresponding to about $1 \mathrm{~h} / \mathrm{d}$ ).

The number of times calves licked their scrotal area declined in the weeks after the procedure, but this reduction occurred more slowly for calves castrated with the rubber ring, resulting in an interaction between week and treatment (Figure 2b; $F_{1,143}=5.21$, $P=0.024)$. We recorded $31 \pm 3.1$ licks/d for calves in the rubber ring treatment versus $15 \pm 1.0 \mathrm{licks} / \mathrm{d}$ for the surgical treatment. Total number of lesion licks per calf averaged $243 \pm 26.3$ for the rubber ring treatment versus $121 \pm 16.9$ for the surgical treatment. 


\section{DISCUSSION}

We assessed wound healing, body weight, feed intake, and behavior for $8 \mathrm{wk}$ following surgical and rubber ring castration. Wound healing was faster after surgery than following rubber ring castration. Earlier work showed that complete healing of surgical wounds requires approximately 4 to 5 wk (Fisher et al., 2001; Stafford et al., 2002; Mintline et al., 2014); our results are consistent with this timeline. For nonsurgical methods, scrotal slough-off requires 6 to $10 \mathrm{wk}$, with complete healing of wound requiring several additional weeks (Molony et al., 1995; Fisher et al., 2001; Marti et al., 2017). Differences in inflammation observed in the current study are consistent with these differences in the healing process; the maximum scrotal temperature recorded decreased over time for both treatments but remained almost $2^{\circ} \mathrm{C}$ higher for calves castrated with a rubber ring. We did not observe any evidence of infection in this study; risk of infection may be higher in some environments, as anecdotally reported by Petherick et al. (2015).

Unlike their older counterparts, growth of preweaning calves has not been observed to be affected by castration, regardless of the method (Brown et al., 2015; Marti et al., 2018). In the present study, ADG remained fairly constant throughout the $8 \mathrm{wk}$, but calves in the rubber ring treatment grew more slowly than those surgically castrated. This difference in weight gain was not due to different milk intakes but may be partly explained by calves in the rubber ring treatment initiating calf starter intake more slowly. Milk intake might have been maintained because of the analgesic effects of both nutritive and non-nutritive suckling, as is well known for human infants and rat pups (Blass, 1994).

Rubber ring castration reduced lying time relative to those castrated surgically; this result is consistent with previous work reporting increased restlessness following rubber ring castration (Robertson et al., 1994; Molony et al., 1995). We also found a high frequency of wounddirected behavior (i.e., lesion licking), mostly with the rubber ring. Previous behavioral results indicated that the postoperative pain associated with surgical castration was largely resolved within 2 wk of the procedure (Molony et al., 1995; Meléndez et al., 2017), but that pain persisted for up to $12 \mathrm{wk}$ after the application of the rubber ring or band, as evidenced by lesion licking, decreased time spent lying, abnormal postures, and response to palpation (Molony et al., 1995: 7 wk; Thüer et al., 2007: 12 wk; Marti et al., 2017: 6 wk).

Multimodal analgesia (i.e., sedative, local anesthetic, analgesic) was given for both treatments, but this cannot be expected to provide relief for more than a few days (Coetzee, 2011), likely insufficient for the longerlasting pain associated with the rubber ring method.
Analgesics could be provided for multiple days, but this may be painful for calves depending upon how the drugs are delivered (e.g., via injections; Ede et al., 2018) and imposes additional costs on producers. In our view, it is unlikely that NSAID pain relief would be provided over the many weeks that calves are experiencing pain following rubber ring castration. Prolonged treatment may even be undesirable, as little is known about the effects of long-term administration of NSAID treatment in young ruminants. On the basis of the current results, we recommend that producers favor the use of surgical castration with multimodal analgesia.

This study had some limitations. We recognize that measures of feed intake or restlessness are not specific to pain (see McLennan et al., 2019) and thus may also suffer from poor sensitivity. However, the choice of pain measures must account for the context of the study (Bateson, 1991; Rutherford, 2002; Sneddon et al., 2014); given the long duration and potentially cumulative effects of the pain experienced by calves in this study, we suggest that less-specific but arguably more integrative behavioral and physiological measures, such as weight gain, are of value. Future work could more specifically explore the affective component of pain by using preference/avoidance paradigms, following recent work on disbudding (Ede et al., 2019).

\section{CONCLUSIONS}

With multimodal pain control, preweaning calves recovered more rapidly after surgical castration, as evidenced by improved wound healing and higher BW gains and solid feed intake. In contrast, calves castrated with a rubber ring showed more scrotal inflammation, reduced lying times, and increased wound-directed behaviors for at least 8 wk after the procedure.

\section{ACKNOWLEDGMENTS}

We thank Benjamin Lecorps, Marrah G. Pfister, and the staff and students of the University of British Columbia (UBC) Dairy Education and Research Centre (Agassiz, BC, Canada) who helped with this study. This work was supported by the Natural Sciences and Engineering Research Council of Canada (Ottawa, ON) Discovery grant RGPIN-2016-04620 awarded to DMW and a Natural Sciences and Engineering Research Council Research Tools and Instruments grant RGPIN-10R75937 awarded to MvK. General funding for the UBC Animal Welfare program is provided by the Natural Science and Engineering Research Council's Research Chair in Dairy Cattle Welfare awarded to DMW and MvK, with contributions from our industrial partners the Dairy Farmers of Canada (Ottawa, ON), 
Saputo Inc. (Montreal, QC, Canada), British Columbia Dairy Association (Burnaby, BC Canada), Alberta Milk (Edmonton, AB, Canada), Intervet Canada Corporation (Kirkland, QC, Canada), Boehringer Ingelheim Animal Health (Burlington, ON, Canada), BC Cattle Industry Development Fund (Kamloops, BC, Canada), the Semex Alliance (Guelph, ON, Canada), Lactanet (Sainte-Anne-de-Bellevue, QC, Canada), Dairy Farmers of Manitoba (Winnipeg, MB, Canada), and SaskMilk (Regina, SK, Canada). The authors have not stated any conflicts of interest.

\section{REFERENCES}

Bateson, P. 1991. Assessment of pain in animals. Anim. Behav. 42:827839. https://doi.org/10.1016/S0003-3472(05)80127-7.

Blass, E. M. 1994. Behavioral and physiological consequences of suckling in rat and human newborns. Acta Paediatr. 83(Suppl. 397):71-76. https://doi.org/10.1111/j.1651-2227.1994.tb13268.x.

Bretschneider, G. 2005. Effects of age and method of castration on performance and stress response of beef male cattle: A review. Livest. Prod. Sci. 97:89-100. https://doi.org/10.1016/j.livprodsci .2005 .04 .006

Brown, A. C., J. G. Powell, E. B. Kegley, M. S. Gadberry, J. L. Reynolds, H. D. Hughes, J. A. Carroll, N. C. Burdick Sanchez, Y. V. Thaxton, E. A. Backes, and J. T. Richeson. 2015. Effect of castration timing and oral meloxicam administration on growth performance, inflammation, behavior, and carcass quality of beef calves. J. Anim. Sci. 93:2460-2470. https://doi.org/10.2527/jas .2014-8695.

Coetzee, J. F. 2011. A review of pain assessment techniques and pharmacological approaches to pain relief after bovine castration: Practical implications for cattle production within the United States. Appl. Anim. Behav. Sci. 135:192-213. https://doi.org/10.1016/j applanim.2011.10.016.

Ede, T., B. Lecorps, M. A. G. von Keyserlingk, and D. M. Weary. 2019. Calf aversion to hot-iron disbudding. Sci. Rep. 9:5344. https: //doi.org/10.1038/s41598-019-41798-7.

Ede, T., M. A. G. von Keyserlingk, and D. M. Weary. 2018. Approachaversion in calves following injections. Sci. Rep. 8:9443. https://doi .org/10.1038/s41598-018-27669-7.

Fisher, A. D., T. W. Knight, G. P. Cosgrove, A. F. Death, C. B. Anderson, D. M. Duganzich, and L. R. Matthews. 2001. Effects of surgical or banding castration on stress responses and behaviour of bulls. Aust. Vet. J. 79:279-284. https://doi.org/10.1111/j.1751 -0813.2001.tb11981.x.

Marti, S., D. M. Meléndez, E. A. Pajor, D. Moya, D. Gellatly, E. D. Janzen, and K. S. Schwartzkopf-Genswein. 2018. Effect of a single dose of subcutaneous meloxicam prior to band or knife castration in 1-wk-old beef calves: II. Inflammatory response and healing. J. Anim. Sci. 96:4136-4148. https://doi.org/10.1093/jas/sky291.

Marti, S., D. M. Meléndez, E. A. Pajor, D. Moya, C. E. M. Heuston, D. Gellatly, E. D. Janzen, and K. S. Schwartzkopf-Genswein. 2017. Effect of band and knife castration of beef calves on welfare indicators of pain at three relevant industry ages: II. Chronic pain. J. Anim. Sci. 95:4367-4380. https://doi.org/10.2527/jas2017.1763.

McLennan, K. M., A. L. Miller, E. Dalla Costa, D. Stucke, M. J. Corke, D. M. Broom, and M. C. Leach. 2019. Conceptual and methodological issues relating to pain assessment in mammals: The development and utilisation of pain facial expression scales. Appl. Anim. Behav. Sci. 217:1-15. https://doi.org/10.1016/j .applanim.2019.06.001.

Meléndez, D. M., S. Marti, E. A. Pajor, D. Moya, C. E. M. Heuston, D. Gellatly, E. D. Janzen, and K. S. Schwartzkopf-Genswein. 2017. Effect of band and knife castration of beef calves on welfare indica- tors of pain at three relevant industry ages: I. Acute pain. J. Anim. Sci. 95:4352-4366. https://doi.org/10.2527/jas2017.1762.

Mintline, E. M., A. Varga, J. Banuelos, K. A. Walker, B. Hoar, D. Drake, D. M. Weary, J. F. Coetzee, M. L. Stock, and C. B. Tucker. 2014. Healing of surgical castration wounds: A description and an evaluation of flunixin. J. Anim. Sci. 92:5659-5665. https://doi .org/10.2527/jas.2014-7885.

Mitlöhner, F. M., J. L. Morrow-Tesch, S. C. Wilson, J. W. Dailey, and J. J. McGlone. 2001. Behavioral sampling techniques for feedlot cattle. J. Anim. Sci. 79:1189. https://doi.org/10.2527/2001 $.7951189 \mathrm{x}$

Molony, V., J. E. Kent, and I. S. Robertson. 1995. Assessment of acute and chronic pain after different methods of castration of calves. Appl. Anim. Behav. Sci. 46:33-48. https://doi.org/10.1016/0168 -1591(95)00635-4.

Nogues, E., M. A. G. von Keyserlingk, and D. M. Weary. 2021. Data for "Pain in the weeks following surgical and rubber ring castration in dairy calves". Scholars Portal Dataverse. https://doi.org/https: //doi.org/10.5683/SP3/4VOZKN.

Petherick, J. C., A. H. Small, D. J. Reid, I. G. Colditz, and D. M. Ferguson. 2015. Welfare outcomes for 3- and 6-month-old beef calves in a tropical environment castrated surgically or by applying rubber rings. Appl. Anim. Behav. Sci. 171:47-57. https://doi.org/10 .1016/j.applanim.2015.08.018.

Renaud, D. L., T. F. Duffield, S. J. LeBlanc, D. B. Haley, and D. F. Kelton. 2017. Management practices for male calves on Canadian dairy farms. J. Dairy Sci. 100:6862-6871. https://doi.org/10.3168/ jds.2017-12750.

Robertson, I. S., J. E. Kent, and V. Molony. 1994. Effect of different methods of castration on behaviour and plasma cortisol in calves of three ages. Res. Vet. Sci. 56:8-17. https://doi.org/10.1016/0034 $-5288(94) 90189-9$

Rutherford, K. M. D. 2002. Assessing pain in animals. Anim. Welf. 11:31-53.

Sneddon, L. U., R. W. Elwood, S. A. Adamo, and M. C. Leach. 2014. Defining and assessing animal pain. Anim. Behav. 97:201-212. https://doi.org/10.1016/j.anbehav.2014.09.007.

Spooner, J. M., C. A. Schuppli, and D. Fraser. 2012. Attitudes of Canadian beef producers toward animal welfare. Anim. Welf. 21:273283. https://doi.org/10.7120/09627286.21.2.273.

Stafford, K. J., and D. J. Mellor. 2005. The welfare significance of the castration of cattle: A review. N. Z. Vet. J. 53:271-278. https://doi .org/10.1080/00480169.2005.36560.

Stafford, K. J., D. J. Mellor, S. E. Todd, R. A. Bruce, and R. N. Ward. 2002. Effects of local anaesthesia or local anaesthesia plus a nonsteroidal anti-inflammatory drug on the acute cortisol response of calves to five different methods of castration. Res. Vet. Sci. 73:61-70. https://doi.org/10.1016/S0034-5288(02)00045-0.

Thüer, S., S. Mellema, M. G. Doherr, B. Wechsler, K. Nuss, and A. Steiner. 2007. Effect of local anaesthesia on short- and long-term pain induced by two bloodless castration methods in calves. Vet. J. 173:333-342. https://doi.org/10.1016/j.tvjl.2005.08.031.

USDA-NASS (USDA National Agricultural Statistics Service). 2021. United States and Canadian Cattle and Sheep. Accessed Apr. 6, 2021. https://downloads.usda.library.cornell.edu/usda-esmis/ files/474299142/d791t878n/3f4630186/uscc0321.pdf

Warnock, T. M., T. A. Thrift, M. Irsik, M. J. Hersom, J. V. Yelich, T. D. Maddock, G. C. Lamb, and J. D. Arthington. 2012. Effect of castration technique on beef calf performance, feed efficiency, and inflammatory response. J. Anim. Sci. 90:2345-2352. https://doi .org/10.2527/jas.2011-4511.

\section{ORCIDS}

Emeline Nogues () https://orcid.org/0000-0001-6040-5833 Marina A. G. von Keyserlingk (- https://orcid.org/0000-0002-1427 $-3152$

Daniel M. Weary @ https://orcid.org/0000-0002-0917-3982 